\title{
Editorial
}

\section{Role of carmustine wafers in the treatment of GBM}

\author{
Bhavuk Kapoor ${ }^{1, *}$, Anil Kansal ${ }^{1}$, Rohit Bansil ${ }^{1}$, Siddharth Mittal ${ }^{1}$, Jerina ${ }^{1}$ \\ ${ }^{1}$ Dept. of Neurosurgery, BLK-Max Super Speciality Hospital, Delhi, India
}

\section{A R T I C L E I N F O}

\section{Article history:}

Received 21-12-2021

Accepted 30-12-2021

Available online 16-01-2022
This is an Open Access (OA) journal, and articles are distributed under the terms of the Creative Commons Attribution-NonCommercial-ShareAlike 4.0 License, which allows others to remix, tweak, and build upon the work non-commercially, as long as appropriate credit is given and the new creations are licensed under the identical terms.

For reprints contact: reprint@ipinnovative.com

\section{Background}

Glioma is the most common type of primary brain tumors. The majority of the grade IV subtype is glioblastoma multiforme (GBM). ${ }^{1}$

GBM, with an approximate incidence of 74,000 cases around the world every year, accounts for nearly $60 \%$ of primary brain tumors.

The treatment of patients with malignant glioma, including surgery followed by radiotherapy and/or chemotherapy, has remained relatively unchanged for 30 years.

Gliadel wafer, a biodegradable polymer containing $3.85 \%$ carmustine (1,3- bis[2-chloroethyl]-1-nitrosourea $[\mathrm{BCNU}])$, is implanted in the resection cavity, delivering carmustine directly at the time of surgery.

These wafers could supply a controlled release of $7.7 \mathrm{mg}$ $\mathrm{BCNU}$ for around 5 days.

BCNU alkylate the nucleoprotein and interfere with the DNA synthesis and repair, and the carbonylation of nucleoprotein lysine residues can also decrease RNA and protein synthesis.

\section{Case Discussion}

A 46 year old, previously operated case of GBM in 2020 (Post radio and chemotherapy) was admitted at

\footnotetext{
* Corresponding author.

E-mail address: kapoorbhavuk14@gmail.com (B. Kapoor).
}

BLK hospital with complaints of progressively increasing headache.

Patient was conscious, cooperative and oriented to time, place and person with right sided hemiparesis.

Recent MRI Brain was suggestive of recurrence of lesion in left posterior parietal parasagittal region with mass effect (Figure 1).

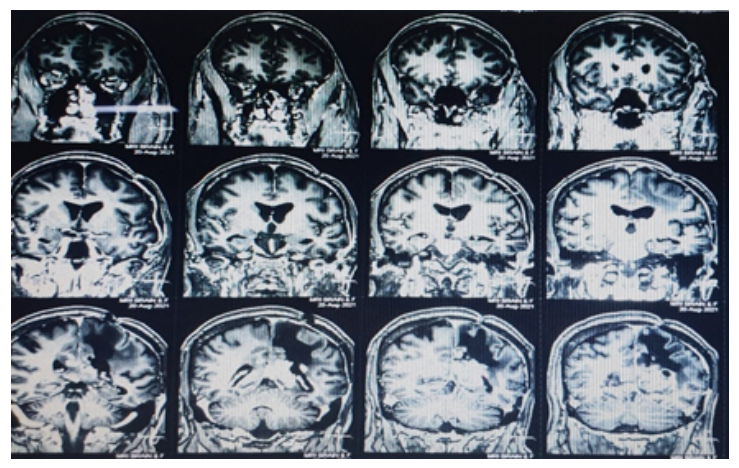

Fig. 1: Preoperative MRI Brain

Patient was planned for surgery. Left parietal craniotomy with excision of lesion was done. Gliadel wafers were carefully placed in the excised recurrent lesion cavity (Figure 2).

Post-operative period was uneventful. Postoperatively screening MRI brain was done (Figure 3). 


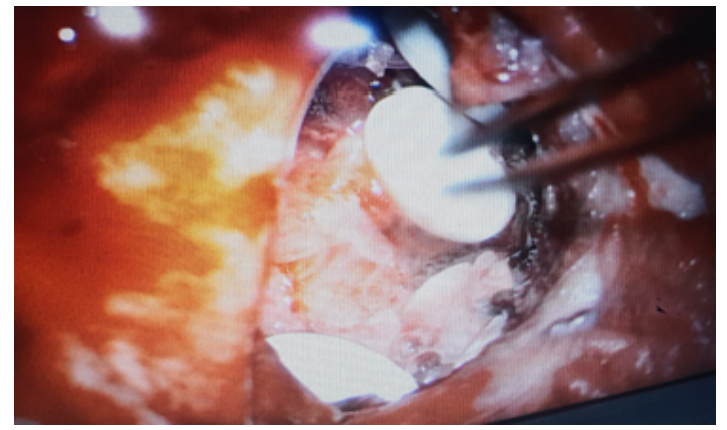

Fig. 2: Placement of Glidal wafers in excisedlesion cavity

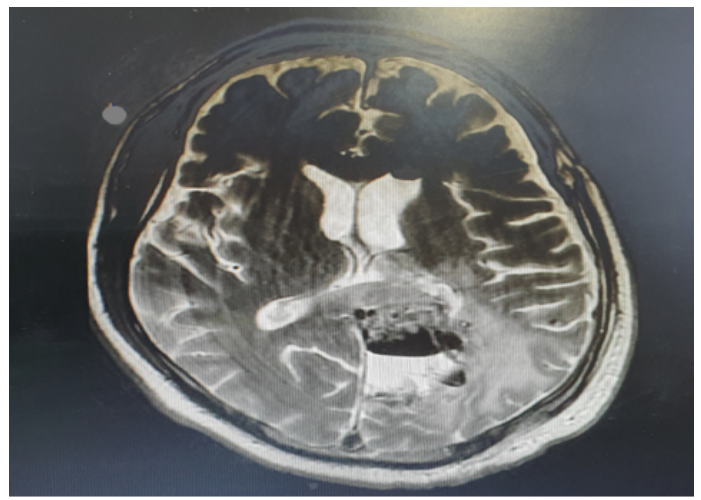

Fig. 3: Post operative screening MRI Brain

\section{Discussion}

GBM is one of the most malignant tumors in human beings. The standard treatment, surgery followed by radiotherapy and temozolomide (Stupp protocol), has been around for several years. However, the survival duration has not increased that much despite striving all the time. Treatment with BCNU wafers along with other adjuvant treatments, being a novel way to raise the $\mathrm{OS}^{2,3}$ has been accepted by neurosurgeons only in recent years. Targeted drug delivery strategies to circumvent the blood-brain barrier have shown efficiency in clinical trials.

Gliadel wafer (Carmustine wafer) is a new approach to the treatment of glioblastoma, which involves controlled release delivery of carmustine from biodegradable polymer directly to the tumor site, thus increasing the clinical effectiveness. Carmustine wafer (CW) implant (Gliadel) is approved for treatment of newly-diagnosed HGG as an adjunct to surgery and radiation and for treatment of recurrent GBM as an adjunct to surgery. ${ }^{4}$ This product is the only US FDA approved chemotherapeutic implant for use during surgical procedures for newly diagnosed, high-grade malignant glioma, as well as for patients with recurrent GBM.

In February 2003, the US FDA approved Gliadel wafer for use in newly diagnosed patients with high-grade malignant gliomas as an adjunct to surgery and radiation therapy. Since its launch, over 20,000 procedures have been performed with Gliadel wafer in the USA alone.

A newly published meta-analysis showed that median survival was only 16 months, and that 1-year and 2-year OS values were $67 \%$ and $26 \%$, respectively, in newly diagnosed HGG patients treated with carmustine wafers. ${ }^{5}$

\section{Conclusion}

Carmustine-impregnated wafers play a significant role in improving survival when used for patients with newly diagnosed and recurrent GBM.

\section{Conflicts of Interest}

The authors declare that there are no conflicts of interest regarding the publication of this paper.

\section{Source of Funding}

None.

\section{References}

1. Dolecek TA, Propp JM, Stroup NE, Kruchko C. CBTRUS statistical report: primary brain and central nervous system tumors diagnosed in the United States in 2005-2009. Neuro Oncol. 2012;14(5):v1-49. doi:Tlog3/newonc/nos 218

2. Bonis PD, Anile C, Pompucci A, Fiorentino A, Balducci M, Chiesa S, et al. Safety and efficacy of Gliadel wafers for newly diagnosed and recurrent glioblastoma. Acta Neurochir (Wien). 2012;154(8):1371-8.

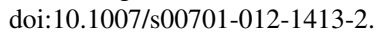

3. Affronti ML, Heery CR, Herndon JE, Rich JN, Reardon DA, Desjardins A, et al. Overall survival of newly diagnosed glioblastoma patients receiving carmustine wafers followed by radiation and concurrent temozolomide plus rotational multiagent chemotherapy. Cancer. 2009;115(5):3501-11. dor:-1002/cncr.24398

4. Eisai Inc. (2010) GliadelR wafer (polifeprosan 20 with carmustine implant). Eisai Inc., Woodcliff Lake, New Jersey.

5. Chowdhary SA, Ryken T, Newton HB. Survival outcomes and safety of carmustine wafers in the treatment of high-grade gliomas: a meta-

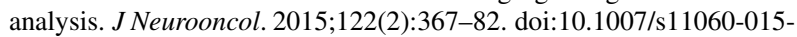
미24-2.

\section{Author biography}

Bhavuk Kapoor, Associate Consultant

Anil Kansal, Director and HOD

Rohit Bansil, Consultant

Siddharth Mittal, Associate Consultant

Jerina, Senior Consultant

Cite this article: Kapoor B, Kansal A, Bansil R, Mittal S, Jerina. Role of carmustine wafers in the treatment of GBM. IP Indian J Anat Surg Head, Neck Brain 2021;7(4):91-92. 